\title{
A systematic review of pharmacological activities and safety of Moringa oleifera
}

\author{
Jacob O. Popoola ${ }^{*}$, Oluwadurotimi S. Aworunse ${ }^{\circledR}$, Olusola L. Oyesola ${ }^{\circledR}$, Olayemi O. Akinnola ${ }^{\circledR}$, Olawole O. \\ Obembe* \\ Department of Biological Sciences, Covenant University, P.M.B. 1023 Ota, Ogun State, Nigeria
}

\section{AR T I C L E I N F O}

Article Type:

Review

\section{Article History:}

Received: 24 December 2019

Accepted: 10 February 2020

\section{Keywords:}

Moringa oleifera

Pharmacological properties

Safety

Toxicity

\begin{abstract}
A B S T R A C T
In the last few decades, Moringa oleifera, a multipurpose medicinal plant (MMP) has received increased research attention and commercial interest for its nutritional, therapeutic and pharmacological properties. Rigorous approaches including biological assays, animal and clinical trials are required towards safe usage as herbal therapy. We conducted a systematic review of the known pharmacological activities, toxicity, and safety of M. oleifera, usually used locally in the treatment and prevention of myriads of illnesses. Five major bibliographic databases (SCOPUS, Web of Science, Science Direct, PubMed, and Mendeley) were searched for studies reported on pharmacological activities, toxicity, and safety assessment of $M$. oleifera in the last 29 years $(1990$ - 2019). Studies on animals and humans involving aqueous leaf extracts and different preparations from M. oleifera seed and bark were also considered. All articles retained, and data collected were evaluated based on the period of the article, country where such studies were conducted and the document type. Our search results identified and analyzed 165 articles while 63 studies were eventually retained. Diverse pharmacological activities including neuroprotective, antimicrobial, antiasthmatic, anti-malaria, cardioprotective, antidiabetic, antiobesity, hepatoprotective and cytotoxic effects, amongst others, were recorded. Toxicity studies in animal models and few human studies showed that $M$. oleifera is safe with no adverse effect reported. The importance of the plant is highlighted in the search for new bioactive compounds to explore its therapeutic potentials towards drug discovery and development in the pharmaceutical and allied industries.
\end{abstract}

Implication for health policy/practice/research/medical education:

This review provides a detailed insight into the pharmacological activities and safety of Moringa oleifera and shows that $M$. oleifera can be used as a reliable source for preparation of new drugs.

Please cite this paper as: Popoola JO, Aworunse OS, Oyesola LO, Akinnola OO, Obembe OO. A systematic review of pharmacological activities and safety of Moringa oleifera. J Herbmed Pharmacol. 2020;9(3):174-190. doi: 10.34172/jhp.2020.24.

\section{Introduction}

Multi-purpose medicinal plants (MMPs) have continued to elicit research interest and commercial attention globally as natural resources considered rich in nutritional and pharmacological properties to treat and cure several diseases $(1,2)$. Several medicinal products as multitherapeutic agents have been derived from such herbs and plants and considered safe for consumption $(3,4)$. Reports indicated that less than $30 \%$ of sub-Sahara Africa's (SSA) population has access to modern health care and pharmaceuticals (5). The other 480 million people in the region rely on traditional medicines, mainly from MMPs $(5,6)$. The medicinal importance and efficacy of the
MMPs have been variously associated with the presence of antioxidants and polyphenolic compounds $(1,7,8)$. In recent years, scientific and commercial efforts are being intensified to advance the sustainable utilization of natural antioxidants from plants in the food and nutrition industry as well as preventive health care (9-12). Over a decade ago, the global market worth of medicinal herbs was estimated to the tune of US\$65 billion and with increased usage of up to US\$5 trillion by 2025 (5). Thus, the relevance of MMPs as a reliable source of nutritive food, medicine and pharmacology will continue to elicit research interest and commercial attention to producing effective pharmaceuticals to combat diseases and 
infections, particularly in the SSA. Ethnopharmacology has proven to be an influential and reliable tool in the search for indigenous plant species with medicinal and pharmacological properties that can be screened for pharmaceuticals toward successful drug discovery and development (13-15). The adoption of herbal medicine is generally hampered by inadequate knowledge of chemical constituents, pharmacokinetics and pharmacodynamics (16). Other limiting factors include poor quality control, scientific and clinical evidence of their efficacy and effectiveness $(17,18)$. In many African traditional herbal remedies, lack of standardization is one of the major constraints to their safety and adoption (19).

In this systematic review, we present $M$. oleifera as one of the valuable MMPs globally recognized as a food and medicinal plant providing natural supplements for healthy living $(1,20,21)$. It is a plant with numerous local utilizations with huge pharmaceutical potentials that can be exploited for human health benefits $(22,23)$. The multipurpose medicinal activities and ethnopharmacological use pattern of $M$. oleifera have been reported from many cultures around the world to treat and cure many illnesses like high fever, diabetes, hypertension, sickle cell anemia and cancer, among others (24-26). Several authors have also reported various bioactivity and pharmacological mechanisms of $M$. oleifera parts including leaf, root, seed, and barks (1,27-30). The hypocholesterolemic activity has been demonstrated in Wistar rats and rabbits $(31,32)$. A detailed review of hyperglycemia and dyslipidemia activities of the plant has also been published by Mbikay (33). Similarly, various parts are widely used in the treatment of neurodegenerative illnesses $(23,25,34,35)$. Precisely, an avalanche of evidence on pharmacological activities has been highlighted in the literature and commercial products attributing such rich activities to the abundant presence of bioactive molecules including antioxidants, flavonoids, quercetin, Moringine among others (36-39).

Globally, there is increased scientific research, commercialization, utilization and demand for M. oleifera based pharmaceutics and supplements to challenge various illnesses and support healthier living. A review of existing literature also indicates commensurate studies on animal models to support and confirm the pharmacological properties and safety of $M$. oleifera. However, safety reports on human studies with no adverse effects are few (40). Herbal extracts and products are limited in use and adoption probably due to the uncertainty surrounding their toxicity level and safety (41). In addition, several reports have shown that toxicity studies are necessary to validate the safety limits of many herbal preparations $(42,43)$. From our observation and market surveys, Moringa-based products and supplements are becoming increasingly available in the open market, as well as online portals without commensurate toxicity assessment tests to establish their safe consumption. Also, different degrees of toxicity have been reported on various seed extracts of M. oleifera and thus requiring more scientific reviews and experimental trials $(42,44)$. Hence, this systematic review is aimed to update existing information on the overall value of the pharmacological activities, toxicity and safety potentials of $M$. oleifera as an MMP.

\section{Methods}

Search strategy

We conducted a systematic review on pharmacological, toxicity and safety of M. oleifera over a period of 29 years (1990 to 2019). Five major databases including PubMed, ScienceDirect, Web of Science, Scopus and Mendeley were engaged in the course of searching for relevant information and data. The search terms were "M. oleifera" and ("pharmacological activities", "safety") without narrowing or limiting search items. Table 1 shows the search terms and combinations. For our search strategy, the systematic procedure reported by Page and Moher (45) was adopted.

\section{Study selection}

Article and study selection was based on originality of research works, keywords and search terms in the title, abstracts and studies involving pharmacological, toxicological and safety assessment of extracts of $M$. oleifera. Inclusion criteria were papers that evaluated the medicinal and pharmacological properties of $M$. oleifera parts (leaves, seeds, and barks) in the treatment of several ailments. We excluded review articles, abstracts, case reports and conference proceedings with no link with our inclusion criteria. The articles were reviewed for titles and abstracts by two reviewers (JOP, OSA) while duplicated articles were eliminated.

\section{Data extraction}

One author (JOP) extracted data using standardized forms. Publications with available abstracts were reviewed.

Table 1. Search terms used for databases

\begin{tabular}{ll}
\hline S/N & Searches* \\
\hline 1 & Moringa oleifera \\
\hline 2 & Pharmacological properties \\
\hline 3 & Pharmacological activities \\
\hline 4 & 2 or 3 \\
\hline 5 & 1 and 4 \\
\hline 7 & Safety \\
\hline 8 & Toxicity \\
\hline 9 & 6 or 7 \\
\hline
\end{tabular}

*Searches on PubMed, Scopus, Science Direct, and Mendeley, Web of Science, followed the same pattern. 
Searched terms and documents were analyzed based on period/year of publication, country/territory, document type (review papers, research papers, books, etc) and subject areas using Excel 2013. The collected information included different types of extracts, pharmacological compounds, and activities, model experiments (animals: rats, mice, clinical trials), the dosage of extracts or drugs and the outcomes. Results were measured in terms of pharmacological and toxicity activities as well as the safety of $M$. oleifera extracts and other preparations. Publications with abstracts on human and animal studies with the main outcome as mentioned above were included. All data were analyzed and presented in the form of a flowchart, charts, tables, and figures.

Quality assessment

We carefully assessed the pharmacological activities, toxicity and safety of $M$. oleifera with clear case definitions. Studies with ambiguous investigations and outcomes were excluded. The procedure of Siqueira-Lima et al (46) was adopted to assess the quality of clinical trials involving a living organism. The studies selected involving random treatment distribution, outcome measurements, and blinded outcome evaluation were analyzed using Excel 2013.

Toxicity and safety studies

Toxicity and safety studies involving animal models and human clinical trials were considered based on histopathology tests, relative organ weights, and toxicity biomarkers.

\section{Results}

After careful searches of databases, we identified and selected 165 articles that clearly matched our selection criteria out of a total of 618 articles searched. The breakdown of the database searches was as follows: 35 articles out of 52 from Scopus, 55 articles out of 456 from ScienceDirect, 50 articles out of 85 from PubMed while 13 from Web of Science and 12 from Mendeley directly related to the purpose of this review were selected. From the 165 articles selected, 50 articles duplicated in two or more databases were excluded leaving us with 115 articles. After preliminary selection of articles based on inclusion benchmarks, a total of 63 published articles were carefully chosen while others were excluded. The data in Figure 1 shows the flowchart of our search strategy. Most of the studies on pharmacological activities, toxicity, and safety on $M$. oleifera were carried out by experts from Indian, Nigeria, South Africa, Italy, Bangladesh, Egypt, Cameroun, Malaysia, Iran among others. Source of articles identified and selected for this review, articles per database searched, year and number of publications as well as geographical location and number of publications were illustrated in Figure 2.

Pharmacological activities of Moringa oleifera

Articles resulting from the search provided information which revealed a high degree of diversity in the pharmacological activities of $M$. oleifera linked to various extracts, fractions, and compounds isolated from $M$. oleifera. Neuroprotective, antimicrobial and antiasthmatic, anti-malaria, cardioprotective, antidiabetic and antiobesity, as well as cytotoxic activities amongst

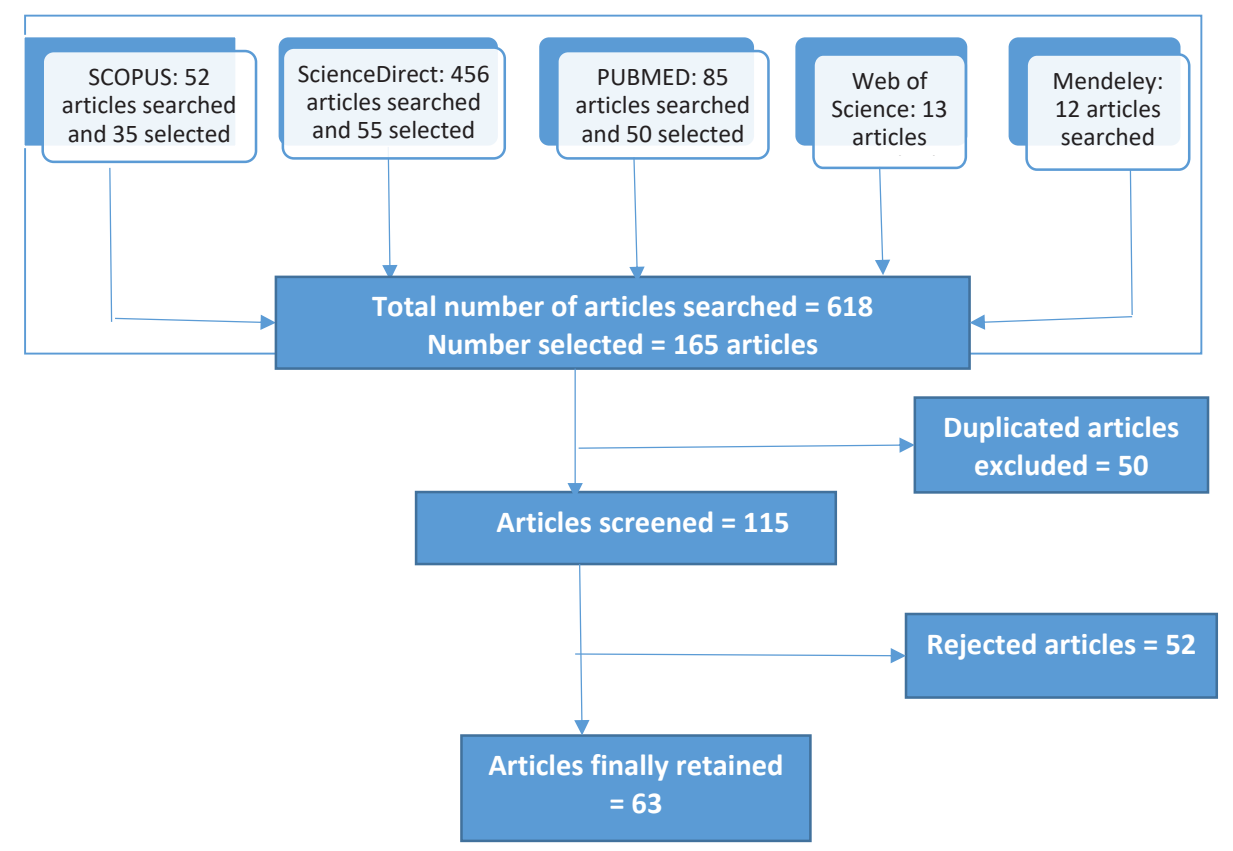

Figure 1. Flowchart of the search strategy and articles included in this review. 

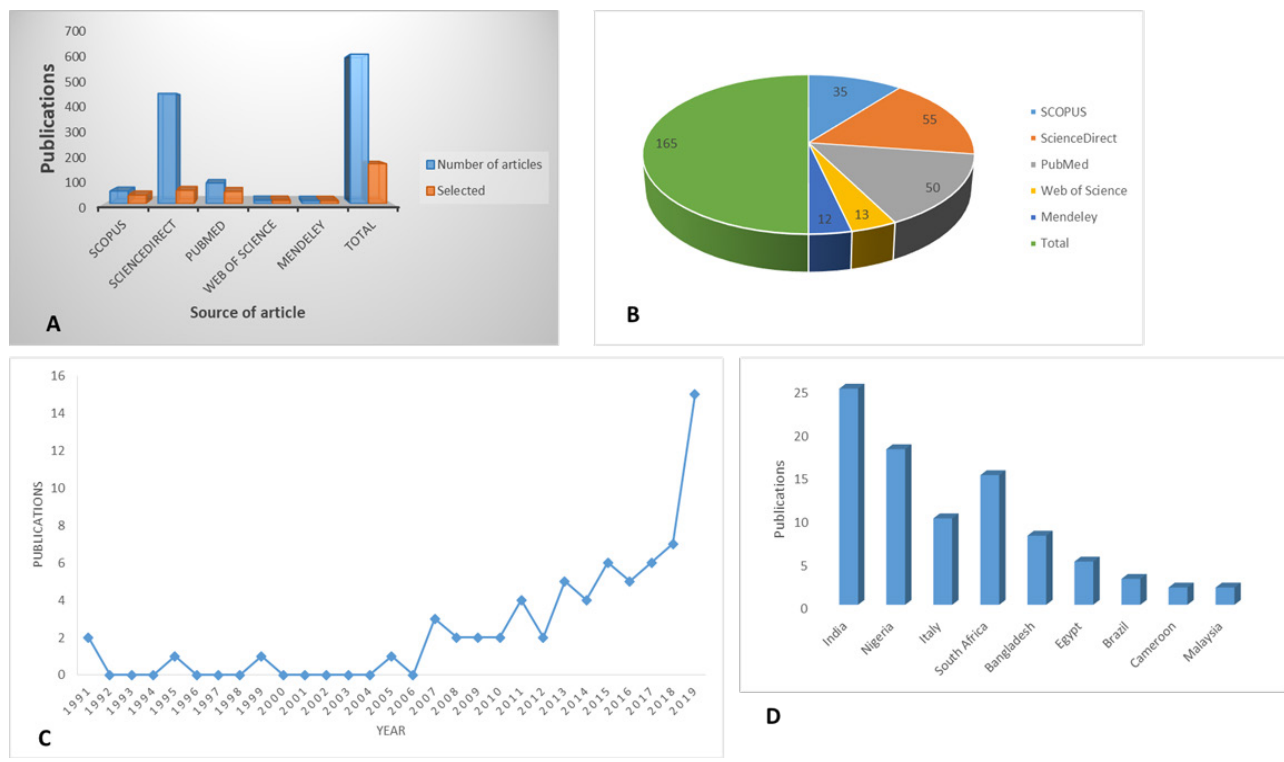

Figure 2. Source of the articles identified and selected for the systematic review according to (A) articles from the different databases, (B) selected articles per database search, (C) year and the number of publications and (D) geographical location and number of publications.

others were recorded (Figure 3). Moringa isothiocyanate was variously mentioned and associated with the pharmacological activities of $M$. oleifera. Information in Table 2 shows the pharmacological properties included in this review, authorship, countries of studies, specific investigation and outcomes.

\section{Toxicity and safety of Moringa oleifera}

Studies on the toxicity and safety of $M$. oleifera included in this review are shown in Table 3. Generally, studies on the toxic effects and safety have reported of M. oleifera to be safe in various models on mice, rats, rabbits, in vitro assays and some clinical trials (42,58-60). In retrospect, very few toxicity and safety evaluations were encountered in investigations involving humans or clinical trials.
Sixteen studies were evaluated on quality assessment of pharmacological studies of $M$. oleifera using experimental animals. Among the articles retained, above $75 \%$ of studies reported and mentioned the random distribution of animals during experimental procedures. Ten studies clearly mentioned sample size while six did not (Figure 4). From the articles retained, doses tested on the experimental subjects showed no adverse effects.

\section{Discussion}

Database searches and global relevance of $M$. oleifera The outcomes of this systematic review confirm that $M$. oleifera is an important plant species with a plethora of pharmacological and therapeutic activities. Our data indicate that Indian researchers were the highest

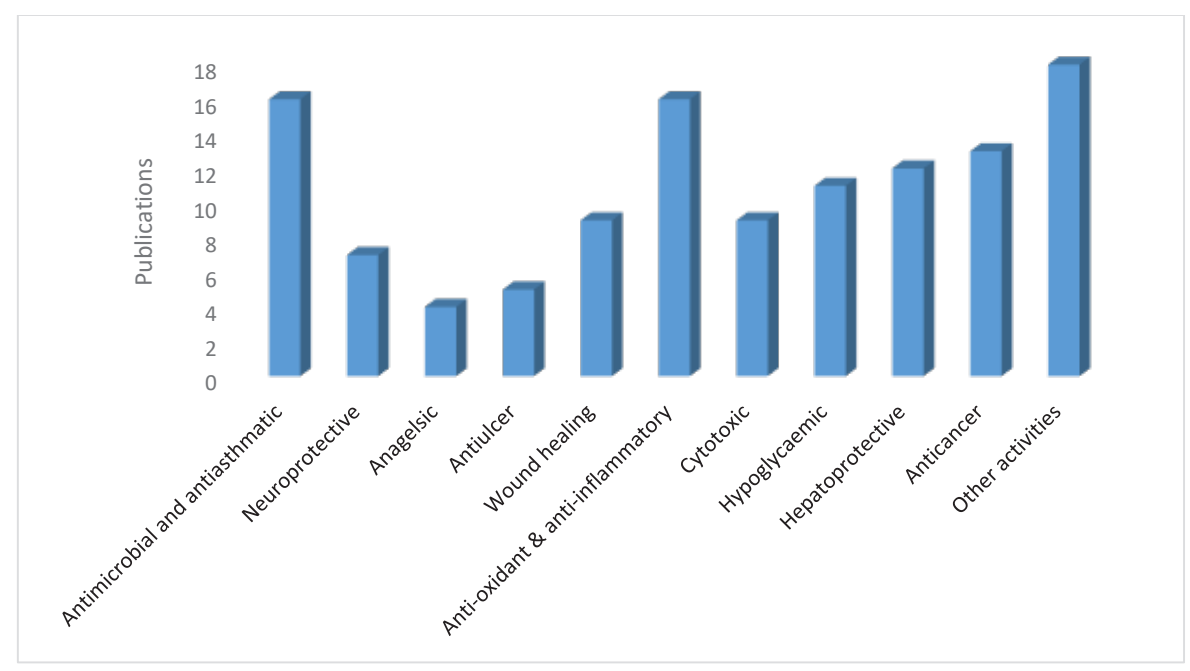

Figure 3. Major pharmacological properties described for Moringa oleifera. 
Table 2. Specific pharmacological properties of Moringa oleifera included in this review

\begin{tabular}{llll}
\hline S/N & Author & Country & Specific investigation \\
\hline 1 & $\begin{array}{l}\text { Moura et al } \\
(47)\end{array}$ & Brazil & $\begin{array}{l}\text { Evaluated the antimicrobial perspective of water-soluble moring } \\
\text { seed lectin on bacteria: Serratia marcescens and Bacillus sp. } \\
\text { Inhibitory effect against } \text { S. marcescens and Bacillus sp. Biofilm } \\
\text { formation studied }\end{array}$ \\
\hline 2. & $\begin{array}{l}\text { Jaja-Chimedza } \\
\text { et al (48) }\end{array}$ & USA & $\begin{array}{l}\text { Comparative studies on the anti-inflammatory activities of } \\
\text { isothiocyanate-enriched MSE, CTE and CEM }\end{array}$
\end{tabular}

(a)

$\begin{array}{ll}\text { Omodanisi et } & \text { South } \\ \text { al (49) } & \text { Africa }\end{array}$

4 Cheraghi et al Iran (50)

Giacoppo et Italy
al (51)

taly

6. Tiloke et al South

(52) Africa

7. Jaafaru et al Malaysia

(53) Malaysia

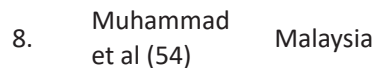
et al (54)

Male Wistar rats were induced with STZ and consequently exposed to methanolic leaf extract of $M$. oleifera to evaluate its anti-oxidant, inflammatory and hypoglycemic activities.

Cardioprotective property of $M$. oleifera leaves using isolated $\mathrm{N}, \alpha-\mathrm{L}-$ rhamnopyranose VR compound was evaluated in rats induced with doxorubicin cardiac toxicity

The study evaluated the antiproliferative properties of $M$. oleifera leaves using isolated isothiocyanate (moringin) complexes on human neuroblastoma cells.

Investigated the anticancer activities of leaf extract of $M$. oleifera on human esophageal Cancer Cell lines

Examined the anticancer effect of Moringa-complex compound: GMG-ITC-RSE on human prostate cancer cells (PC-3).

Wound healing abilities of bioactive $M$. oleifera aqueous fraction on STZ and NAD - induced diabetic Wister rats were evaluated.

Hannan et al Republic

In vitro neuroprotective potential of $M$. oleifera ethanolic leaf extract evaluated.

Evaluation of the antiulcerative activity of polyherbal concoction containing M. oleifera, Raphanus sativus, Amaranthus tricolor leaf extract in experimental model of gastric ulcer in male Albino Wister rats

Devaraj and
Krishna (56)

Manaheji et

al (57)

Iran

Arthritis-induced rats on CFA were subjected to methanolic leaf and root extracts of $M$. oleifera to evaluate the analgesic properties
Findings

Pharmacological properties

The water-soluble M. oleifera Lectin suppressed the formation of biofilm by the bacteria (S. marcescens), Antimicrobial: also inhibited bacterial growth. The lectin also suppressed the growth of Bacillus sp. at the reported concentration.

(antibacterial and antibiofilm)

Moringa isothiocyanate-1 of MSE significantly reduced carrageenan-induced paw edema in SpragueDawley rats at a rate comparable to aspirin, whereas CTE had no significant effect. It significantly inhibited the gene expression of lipopolysaccharide- iNOS, IL-1 $\beta$ and IL-6 and NO production, whereas, at all the concentrations tested, CEM had no significant activity.

A significant reduction in plasma glucose level reported in Moringa treated diabetic rats. The

hypolipidemic activity was demonstrated in diabetic rats. Antioxidant activity was reported to be high

Moringa leaf extract showed a depressing impact on biomarkers-TNF- $\alpha$ and IL-6. Diabetic nephropathy was significantly reduced.

VR reduced MDA levels in heart tissues. Consequent upon administration, reduced SOD and GSH levels were increased. VR administration inhibited the appearance of markers of heart failure.

Cardioprotective

The growth of SH-SY5Y cancer cells was suppressed. MAC treated cells displayed a dosage relian

downregulation of phosphatidylinositol 3-kinase ( $\mathrm{P} 13 \mathrm{~K}$ )/ Akt (protein kinase B)/mammalian target of

rapamycin pathway. MAC treatment also induced apoptotic cell death pathway in the tumor cells.

Anticancer

列

Induction of apoptosis was also observed.

Anti-proliferative effects on PC-3 cells were reported while the safety of the Glucomoringin-

isothiocyanate rich soluble extracts was confirmed.

Antibacterial susceptibility testing revealed that Moringa oleifera aqueous fraction repressed bacteria growth on chronic wounds of diabetes (S. aureus, P. aeruginosa, and E. coli). The bioactive fraction of Moringa enhanced wound healing in diabetic rats by downregulating proinflammatory cytokines and promoting angiogenesis.

Leaf extract dose-dependently increased number, length, and branching of neuritis. Moringa leaf extract protected neurons against naturally occurring cell injury by significantly increasing neuronal viability, enhanced neuronal differentiation and synaptogenesis.

Polyherbal concoction exhibited significant antiulcer activity. Herbal formulation was reported to be efficacious in preventing stomach sores caused by reperfusion and ischemia, ethanol and indomethacin.

Anti-inflammator

nd anti-oxidant

The extracts considerably reduced symptoms of pain,
hyperalgesia in tested rats with CFA-induced arthritis

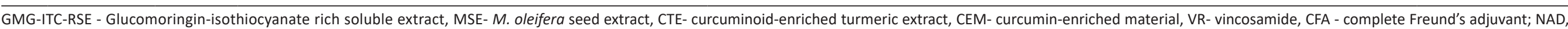
nicotinamide; STZ, Streptozotocin; iNOS, inducible nitric oxide synthase; NO, nitric oxide; IL, interleukin; TNF, tumor necrosis factor; MDA, malondialdehyde; SOD, superoxide dismutase; GSH, glutathione peroxidase. 
Table 3. Toxicity and safety studies of Moringa oleifera included in this review

\begin{tabular}{|c|c|c|c|c|c|}
\hline$S / N$ & Author & Country & $\begin{array}{l}\text { Model } \\
\text { experiment }\end{array}$ & Specific investigation & Findings \\
\hline 1. & $\begin{array}{l}\text { Adedapo et al } \\
\text { (61) }\end{array}$ & Nigeria & Rats & $\begin{array}{l}\text { Oral toxicity and safety of } M \text {. oleifera leaf extracts were investigated in rats at different } \\
\text { standards and higher doses administered for } 21 \text { days. }\end{array}$ & $\begin{array}{l}\text { No adverse effect on studied organ and organism. The extracts were reported to } \\
\text { be safe for consumption in tested organisms. }\end{array}$ \\
\hline 2. & Asare et al (20) & Ghana & Rats and human & $\begin{array}{l}\text { The study evaluated the toxicity and safety of an aqueous leaf extract of } M \text {. oleifera in } \\
\text { different rats and human blood cells. The rats were fed with high doses of the extracts at } \\
1000 \text { and } 3000 \mathrm{mg} / \mathrm{kg} \text { of and observed for two weeks. Outer blood mononuclear cells in } \\
\text { humans were also subjected to graded doses of the extract. }\end{array}$ & $\begin{array}{l}\text { No toxicity was recorded at low and standard doses but at a very high dose of } \\
3000 \mathrm{mg} / \mathrm{kg} \text { b.wt, the extracts were genotoxic. The dose of } 3000 \mathrm{mg} / \mathrm{kg} \text { was too } \\
\text { high which exceeded the recommended doses. Thus, at recommended/standard } \\
\text { doses, no traces of genotoxicity were found both in rat's human cells examined. }\end{array}$ \\
\hline 4 & Kim et al (42) & USA & Rats & $\begin{array}{l}\text { Toxicity evaluation to determine the safety of Moringa isothiocyanate- } 1 \text {-enriched hydro- } \\
\text { alcoholic MSE was investigated in rats. Toxicity was determined in various internal organs } \\
\text { and cells: gastrointestinal and stomach lesion and discoloration among others. }\end{array}$ & $\begin{array}{l}\text { No mortality was recorded at normal, mid-high and mid-low dose groups. } \\
\text { However, mortality was observed in group fed with very high doses of the extracts. }\end{array}$ \\
\hline 5 & $\begin{array}{l}\text { Villarruel-Lopez } \\
\text { et al (62) }\end{array}$ & Mexico & $\begin{array}{l}\text { Sprague Dawley } \\
\text { rats }\end{array}$ & $\begin{array}{l}\text { Toxicity and genotoxicity of leaf powder of } M \text {. oleifera administered at different doses } \\
\text { were evaluated in rats using LD50 and micronuclei assay. Different organs were observed } \\
\text { by the hematoxylin-eosin technique. }\end{array}$ & $\begin{array}{l}\text { Tested doses were not lethal on experimental rats. Genotoxicity parameter were } \\
\text { not statistically significant. }\end{array}$ \\
\hline 7 & $\begin{array}{l}\text { Awodele et al } \\
\text { (58). }\end{array}$ & Nigeria & Mice & $\begin{array}{l}\text { The toxic effect of } M \text {. oleifera aqueous leaf extracts on mice was evaluated using oral } \\
\text { administration of } 6400 \mathrm{mg} / \mathrm{kg} \text { extracts and intraperitoneal dose of } 1500 \mathrm{mg} / \mathrm{kg} \text {. In another } \\
\text { trial, the mice were orally administered different doses for } 60 \text { days. }\end{array}$ & $\begin{array}{l}\text { No toxicity level recorded on examined organs and cells. The study concluded } \\
\text { that leaf extracts of } M \text {. oleifera were safe in the experimental animals used. }\end{array}$ \\
\hline 8 & $\begin{array}{l}\text { Oyagbemi et al } \\
\text { (63). }\end{array}$ & Nigeria & Wista Rats & $\begin{array}{l}\text { The study investigated the toxicity of } M \text {. oleifera methanolic extracts at differing dosages } \\
\text { in } 30 \text { Wistar rats for } 2 \text { months. }\end{array}$ & No adverse effect reported \\
\hline 9 & $\begin{array}{l}\text { Agrawal and } \\
\text { Mehta (64) }\end{array}$ & & $\begin{array}{l}\text { Clinical trial } \\
\text { (Human) }\end{array}$ & $\begin{array}{l}\text { Antiasthmatic effect of } M \text {. oleifera seed kernels on bronchial asthma of } 20 \text { asthmatic } \\
\text { patients was investigated. Toxicity was also evaluated on the patients }\end{array}$ & No adverse effect reported and that $M$. oleifera seed kernels were safe. \\
\hline
\end{tabular}

MSE, Moringa seeds extract. 


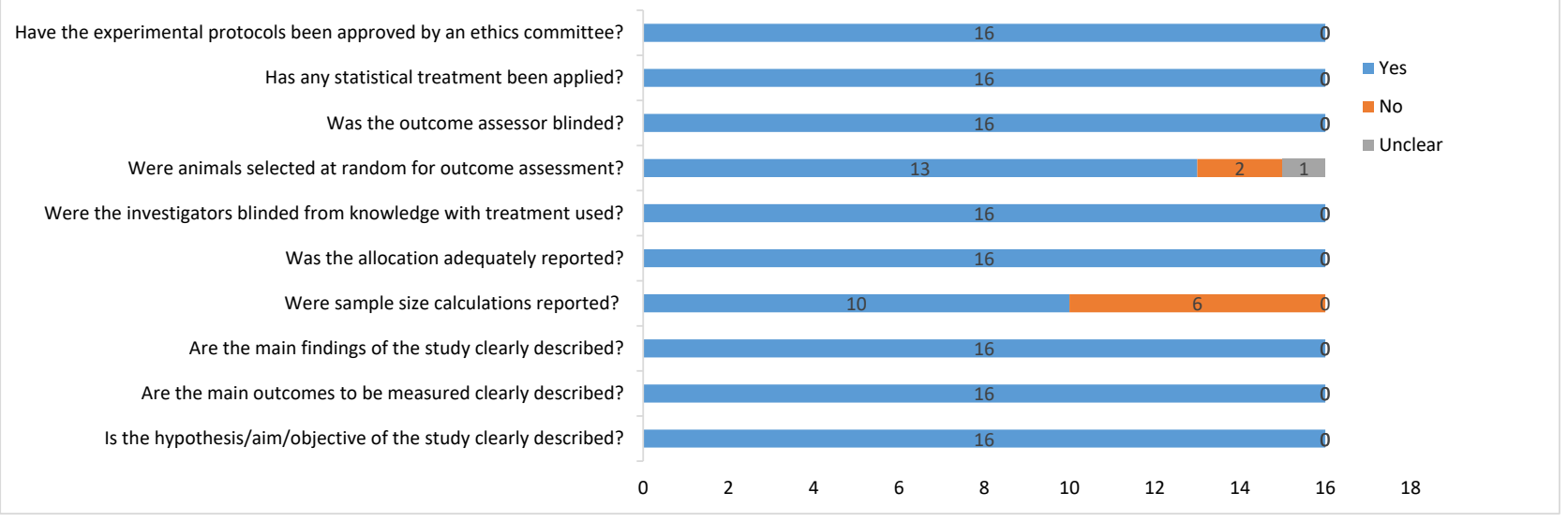

Figure 4. Methodological quality of preclinical pharmacological studies. Articles considered for each criterion adopted are represented on the chart.

investigators on M. oleifera utilization and exploitation followed by those from Nigeria. There was also a steady rise in publications from 1991 and to a peak in 2018/2019. The high number of articles returned from searches, those retained and the spread of articles that cut across Africa, Asia, the Middle East, Europe, and America is an indication of global research interest on M. oleifera. This is unprecedented and comprehensive in recent times. The articles were inclusive and detailed enough to understand the mechanisms of the pharmacological activities, toxicity, and safety of $M$. oleifera as a herbal source. Scientific investigations over the last 29 years on M. oleifera have been impressive and substantiated many of the traditional folklore claims on the plant. These can be further explored for drug development and nutritional enhancement using genetic-based approaches and smart-technologies. The positive correlation between the intake of $M$. oleiferaenriched foods and reduction in the risk of having certain types of non-communicable diseases also confirm the rich pharmacological properties of the plant $(65,66)$. Overall, the bioactive components in $M$. oleifera have been well researched, isolated and documented to promote good health and living (66). This review summarizes the pharmacological activities and safety of M. oleifera as a reliable source of new drugs in the near future.

Pharmacological activities of M. oleifera

Anti-oxidant and free radical scavenging activities/ properties

A high number of articles retained for the pharmacological activities reported the anti-oxidant and free radical scavenging activities of $M$. oleifera. Anti-oxidants are usually reducing agents like ascorbic acid, thiols, and polyphenols that reduce signs of aging, the risk of heart attacks and stroke $(44,67)$. Articles reviewed indicate that $M$. oleifera is rich in antioxidants and phenolics with the ability to stabilize free radicals produced in cells to tolerate electrons. Recently, the antioxidant activities of isothiocyanate-enriched $M$. oleifera seed extract were recommended as good botanical leads to mitigate inflammatory-mediated chronic disorders (48). Adedapo et al (44) also validated the antioxidant capabilities of $M$. oleifera leaf extracts with the potentials to relieve pains without toxic reactions. Several other studies have outlined the analgesic, anti-oxidant and free radical scavenging capabilities of $M$. oleifera as a multi-purpose medicinal plant $(44,68,69)$. The in vitro and ex vivo antioxidant, hypolipidaemia and antiatherosclerotic capabilities of $M$. oleifera leave extract have been demonstrated in rats as an active therapeutic agent against cardiovascular diseases (70,71). Adepoju-Bello et al (72) investigated the in vitro antioxidant properties of $M$. oleifera using 1,1-diphenyl -2-picryl hydrazil (DPPH) scavenging assay. The outcomes confirmed that, among the different doses used, $50 \%$ of M. oleifera ethanolic extract at a dose of $300 \mathrm{mg} / \mathrm{kg}$ was superior with very high antioxidant capabilities, restored weight and pronounced hypoglycaemic effect in Wistar rats (72).

\section{Anti-inflammatory and analgesic activities}

Over $75 \%$ of the articles retained highlighted the antiinflammatory and pain relieving activities of M. oleifera which also have been associated with the plant's high antioxidants content. We noticed increased investigation on the anti-inflammatory, antitumor and anticancer abilities of M. oleifera. Inflammation is a multifarious biological reaction of vascular cells to detrimental stimuli, for instance, pathogenic infections, injured cells or irritations $(44,73)$. It is a protecting effort/mechanism by which organisms tend to get rid of harmful impetuses and initiate the healing process (44). Pain, heat, redness, swelling, and loss of functions are some of the usual symptoms of acute inflammation (74). Adedapo et al (75) validated the antioxidant, anti-inflammatory and antinociceptive capabilities of the methanolic extract of M. oleifera foliage. The analgesic effects of M. oleifera 
methanolic leaf and root extracts on induced arthritis in rats also established that the extracts considerably reduced all the mechanical symptoms of pain and inflammation among the studied rats (57). A depressing outcome on the inflammatory biomarkers-tumor necrosis factor (TNF- $\alpha$ ) and IL-6 diabetic nephropathy in streptozotocin-induced diabetic male Wistar rats were also observed (76). Thus, the analgesic and anti-inflammatory capabilities of $M$. oleifera parts are not in doubt and could be carefully explored as a cheap and effective drug source to relieve pain and treat inflammation-related disorders.

\section{Anti-microbial and antiasthmatic activities}

Plant-based sources of cheaper, effective and reliable antibiotics to combat many human and agricultural infectious diseases are gaining scientific attention around the world. Findings from this review showed that M. oleifera is one of those plant species with proven pieces of evidence of abundant antioxidants and antimicrobial capabilities (77). Caceres et al(39) investigated the leaves, seeds, barks, and roots of $M$. oleifera against many microorganisms and established the anti-microbial effects of the studied $M$. oleifera parts. The presence of 4-(alpha-L-rhamnosyloxy) benzyl isothiocyanate (1) and 4-(4'-O-acetyl-alphaL-rhamnosyloxy)-benzyl isothiocyanate have been implicated in the antimicrobial capabilities of the plant $(39,78,79)$. For instance, in the studies of Padla et al (78), the bioactive complexes (isothiocyanate 1 \& 2) screened for antimicrobial capabilities against certain microbes were implicated to inhibit the growth of grampositive bacteria and other microbes. Elgamily et al (80) explored the alcoholic extracts of $M$. oleifera parts for dental antibacterial and antifungal abilities with resultant inhibition against Staphylococcus aureus and S. mutans. In all the articles retained, isothiocyanate complexes were highlighted to be responsible for its antimicrobial activities. $M$. oleifera leaf extracts were also found to be potent against infectious diseases caused by multidrug-resistant gram-negative bacteria (81). The investigation of Moura et al (47) clearly established the antimicrobial capabilities of the seed lectins from $M$. oleifera found to suppress the formation of biofilm by $S$. marcescens and inhibited bacterial growth. The lectin also suppressed the growth of Bacillus sp. With respect to the antiasthmatic activity of the species, a clinical evaluation of seed kernels on twenty asthmatic patients indicated its efficacy and safety to treat asthma in human clinical trials (64). According to the study, alkaloid moringine relaxes bronchioles which closely bear a resemblance to ephedrine in action and valuable to treat asthma and other related ailments. Based on the noticeable reduction in asthma symptoms and improved breathing functions of the patients, $M$. oleifera is a very potent herbal source that can be used in asthma prevention and treatment. Infectious diseases are the main cause of death in teenagers $(39,81)$. It is common in developing nations with high mortality being recorded every year (81). Consequently, bacteria are increasingly becoming resistant to antibiotics as a result of a change in response to the use of antibiotics, overuse, and misuse (81-83). Antibiotics resistance is currently a leading threat in the health sector. The $\mathrm{WHO}$ at a recent press conference organized to commemorate the 2018 world antibiotics and diabetes awareness week in Nigeria cautioned the public against the misuse of antibiotics and urged healthy feeding as well as physical exercise to combat diabetes (Read more at https://www.vanguardngr.com/2018/11/who-cautionsagainst-misuse-of-antibiotics).

\section{Cytotoxicity, neuroprotective and anti-cancer activities}

The various dietary and behavioural risks causing cancer include indulgence in tobacco and alcohol use, inadequate consumption of fruits and vegetables, lack of physical activities and obesity. Conventional chemotherapy is often characterized by known and unknown sideeffects. Consequently, plant-based alternative drugs and remedies are vigorously being explored as possible therapeutic agents. Findings from this review show that M. oleifera contains rich bioactive compounds which can be harnessed in the treatment and management of chronic diseases including cancer, HIV/AIDS amongst others (84). The antitumor actions of $M$. oleifera have been connected to the two-well characterized phytochemicals moringinine and quercetin which reverses tumourigenesis $(85,86)$. The recent study of Jaafaru et al $(60)$ provided more insight into the neuroprotection activities of $M$. oleifera isothiocyanate against hydrogen peroxideinduced oxidative stress. The isolated compounds, 4-( $\alpha-\mathrm{L}-$ rhamnopyranosyloxy) benzyl ITC (moringin) complexed with alpha-cyclodextrin (moringin $+a-C D ; M A C$ ), were shown to possess antiproliferative capabilities on $\mathrm{SH}$ SY5Y human neuroblastoma cells $(53,60)$. The nontoxic M. oleifera complexes induced apoptosis and inhibited the metastasis of cancer cells in man (60). In similar studies, isothiocyanate from $M$. oleifera seeds was demonstrated to mitigate hydrogen peroxide-induced cytotoxicity and maintained human neuronal cell morphology (53). Previous studies have also shown the antioxidants and anticancer capabilities of $M$. oleifera crude and aqueous extract with the ability to induce reactive oxygen species (ROS) $(87,88)$. In addition, the antiproliferative activities on two cancer cells HepG2 (liver carcinoma cell line) and MCF7 (breast cancer cell line) confirmed M. oleifera as a probable source of cancer therapy $(52,89,90)$. In another study, the beneficial effect of root extract of $M$. oleifera was evaluated against beryllium-induced oxidative stress in rats (91). The study confirmed that $M$. oleifera with piperine therapy was potent, while the mixture of $M$. oleifera and curcumin was more active and showed better therapeutic outcomes. The potential anticancer efficacy of the plant using the leaf ethanolic extracts has also 
been demonstrated in human cancer cells such as breast cancer cell type MDA-MB-231, HCT-8 (colorectal) cells and A549 lung cancer cells $(89,92)$. Phytonanoparticles of $M$. oleifera and its potential antiproliferative agents against cancer are consistent with the safety reports and clinical responses on $M$. oleifera utilization to treat and cure cancer, neuroblastoma and other related diseases $(64,93,94)$. Suppression of tumor growth and induction of apoptosis on Ehrlich's solid tumor implanted mice also indicated a reliable anti-tumor/anti-cancer capabilities of $M$. oleifera leaf extracts (95). With the preponderance of scientific reports on the cytotoxicity, neuroprotective and anticancer capabilities of M. oleifera parts, it is hoped that pharmaceutical companies around the globe will step in and develop Moringa-based drugs to cure cancer and other degenerative diseases.

\section{Anti-diabetic and anti-obesity activities}

People around the world have exploited herbal medicine to solve their health challenges and ultimately for a healthier living (96). Diabetes, being a protracted metabolic malady of the endocrine system, is characterized by abnormalities in carbohydrates, protein, and fat metabolism $(97,98)$. The incidence of diabetes is increasing at an alarming rate with the attendant high cost of management/treatment and its related complications (96,99-101). In 2012 alone, diabetes caused 1.5 million deaths with an increased projection estimated in recent years $(99,101)$. Stroke, heart attack, overweight, kidney failure, obesity, leg amputation, vision loss, and nerve damage are some of the complications of diabetes. Obesity in Africa is also on the increase, being associated with various medical conditions that may lead to death. An imbalance in the intestinal flora is one of the main factors related to obesity and metabolic disorders. The human gut microbiome undertakes a variety of metabolic functions such as the breakdown of complex organic substances into easily digestible sources of energy. $M$. oleifera possesses antidiabetic, hypo- and hyperglycemia effects $(1,102)$. Consequently, the antidiabetic therapeutic effect of $M$. oleifera has been attributed to its polyphenols content to reduce blood glucose and lipids concentration after ingestion (96). According to the investigation of Abd Eldaim et al (103), M. oleifera leaves aqueous extract significantly ameliorated hepatotoxicity and reduced hyperglycemia in alloxan-induced diabetic rats. In another study designed to demonstrate the efficacy of M. oleifera ethanolic extract in rats induced with high-fat diet obesity, body weight was significantly reduced in rats treated with the extracts (104). Potential hypoglycemic activity of phenolic glycosides from $M$. oleifera seed also showed significant therapeutic properties in reducing blood pressure, blood sugar and enhancing the immune system in humans (105). M. oleifera leaves extract was thus confirmed to exhibit hypolipidemic and antiobesity potentials with the capacity to protect the body against negative effects of high fat diet-induced obesity. Numerous non-diabetic and diabetic animal studies have demonstrated the antidiabetic effect of $M$. oleifera leaf extracts to reduce plasma glucose levels and increase glucose tolerance $(29,106,107)$. A significant decrease in the level of plasma glucose was reported in rats having diabetes using $M$. oleifera leaves extract (76). The study of Jaiswal et al (107) also established the antidiabetic effect of constant consumption of the leaves of M. oleifera as a therapeutic means to protect diabetic patients against oxidative damage. The leaf preparation of the plant was also shown to significantly ameliorate streptozotocininduced diabetes milletus in adult rats with the outcome of a reduction in biomarkers of diabetes (108). Alejandra Sanchez-Munoz et al (109) recently demonstrated the effect of $M$. oleifera extract on supercomplex formation, ATPase activity, ROS production, glutathione (GSH) level, lipid peroxidation, and protein carboxylation. Their findings indicated that hyperglycemia modifies oxygen consumption, supercomplexes formation, and increases ROS levels of STZ-diabetic rats while M. oleifera treated rats were protected against some alterations. Recently, Leone et al (110) demonstrated the potential hypoglycemic capabilities of the powdered form of the leaves of $M$. oleifera on postprandial blood glucose response on Saharawi people living in refugee camps and confirmed M. oleifera leaf powder as a possible hypoglycemic herbal drug. Several other reports have validated the antidiabetic activities of $M$. oleifera leaf and seed extracts in diabetic rats (62,110-112). Overall, $M$. oleifera leaves were confirmed to lower postprandial blood pressure (50).

\section{Cardioprotective and anti-hypertension activity}

Articles retained on anti-hypertension activities of $M$. oleifera suggest a positive correlation between consumption of raw leaves/extracts of $M$. oleifera and reduction in blood pressure of tested animals. Globally, hypertension, heart failure, and their associated risk factors have been a major cause of death without restriction to age (113) while almost half the losses in dialysis patients are ascribed to heart disease (114). High blood pressure is a typical symptom of hypertension with severe complications and increases the risk of heart disease, stroke, and death $(115,116)$. Findings of different health interventions by the University College Hospital (UCH), Ibadan, Nigeria, indicated that hypertension is the commonest disease after the age of 40 (117). Management and cure for cardiac arrest and hypertension are cumbersome using synthetic drugs and usually with side effects. Thus, natural remedies that reverse hypertension and lowers high blood pressure are being sought after as plausible solutions to cardiovascular ailments. In this regard, our review outcome indicates that M. oleifera is a good candidate useful to treat hypertension. Its parts show cardiac protective effects in spontaneously hypertensive rats (115). Several studies have also provided 
scientific proof in support of ethnopharmacological uses of $M$. oleifera as the antihypertensive plant with strong cardiac protective effects $(118,119)$. Cheraghi et al (50) investigated the cardioprotective property of $M$. oleifera isolated magnetic hydrogel nanocomposite loaded N, $a$-Lrhamnopyranosyl vincosamide (VR) on rats induced with doxorubicin cardiac toxicity. It was shown that VR levels of malondialdehyde (MDA) and superoxide dismutase (SOD) in heart tissues were reduced and heart failure biomarkers were inhibited. The studies of Nandave et al (120) also highlighted the cardioprotective capabilities of $M$. oleifera in isoproterenol (ISP)-induced model of myocardial infarction. Their findings indicated that the effects of ISP-induced hemodynamic perturbations and a rise in lipid peroxidation were significantly repressed when tested organisms treated with $M$. oleifera extracts. The cardioprotective/antihypertension capacities of the plant might not be unconnected to the high content of antioxidant, antiperoxidative, and myocardial preservative activities (130). Previous studies and personal experiences of one of us (JOP) also validate the consumption of $M$. oleifera raw leaves or extracts to lower the blood pressure, enhance sleep and prevent cardiac arrest $(2,24)$.

\section{Wound healing and anti-ulcer activities}

Wound healing and anti-ulcerative pharmacological capabilities of $M$. oleifera have been severally reported and associated with rich phytochemical contents of alkaloids and antioxidants $(59,77,121,122)$. Ulcer is one of the neglected tropical diseases affecting millions of people in many countries of the world (123). It is caused by infection with Mycobacterium ulcerans. Valuable anti-ulcer, anti-secretory and cytoprotective activities of $M$. oleifera were shown in albino Wistar rats using $M$. oleifera ethanolic root-bark extract, which aligns with the preponderance ethnobotanical information on the plant $(24,122)$. Studies of Ruckmani et al $(124)$ revalidated the anti-ulcerative properties of $M$. oleifera root and leaves in alkali preparation with healing effects. The evaluation of polyherbal concoction of $M$. oleifera, Raphanus sativus and Amaranthus tricolor leaf extracts in an experimental model of gastric ulcer in male albino Wistar rats also confirmed the use of $M$. oleifera as anti-ulcer therapy (56). Their findings concluded that polyherbal concoction exhibited significant anti-ulcerative activity, efficacious in preventing stomach sores caused by reperfusion and ischemia, ethanol and indomethacin. In another study, M. oleifera extract was compared with a commonly used drug for the ulcer, famotidine, and found out that the extract and famotidine significantly reduced the free acidity and total acidity of gastric juice (125). Thus, $M$. oleifera preparations, particularly in alkali form, can treat and cure ulcers without any adverse effect. The presence of both tannins and flavonoids has been implicated for the antiulcer activity of $M$. oleifera $(39,125,126)$.
Wound healing has been described as a complex process of tissue repair in response to injury. It is characterized by hemostasis, inflammation, fibroplasia, and maturation $(121,127)$. An aqueous fraction from $M$. oleifera was reported to heal wounds on diabetic Wister rats induced with STZ and nicotinamide (NAD) (54). The study established that $M$. oleifera aqueous fraction inhibited the growth of bacteria associated with chronic wounds of diabetes. The bioactive compound Vicenin-2 was implicated to enhance wound healing in diabetic rats by downregulating proinflammatory cytokines and promoting angiogenesis (54). Alcoholic preparation of $M$. oleifera leaves was also confirmed as an effective therapeutic agent in healing skin wound and improved fibroblast proliferation and spread thereby increasing wound closure rate (121).

\section{Anti-malaria activities}

Malaria is a leading and probably the most upsetting infectious disease with an increased incidence of mortality in sub-Saharan Africa $(128,129)$. The mosquito vector, Plasmodium falciparum, is the cause of malaria infection. Though one study indicated that there is a decline in malaria in many parts of Africa, the estimations are not reliable with many deaths recorded recently $(130,131)$. Malaria challenge is compounded by widespread resistance to artemisinin combination therapies by malaria parasites (132). However, as the threat of antimalarial drug resistance increases, persistent efforts are also being expended in developing alternative therapies coupled with the sustainability of existing treatments and control methods. Over the centuries, the use of herbal combinations or preparations as active antimalarial drugs have been seen as an effective approach to treat recurrent malaria infections $(133,134)$. M. oleifera in combination with other plants has been actively used as antimalarial in many parts of Africa and Asia $(2,24)$. For instance, M. oleifera and Gynostemma pentaphyllum leaf extracts were combined with Artesunate in mice infected with Plasmodium berghei and adjudged effective in the treatment of malaria (135). The infected mice were subjected to artesunate treatment $(6 \mathrm{mg} / \mathrm{kg})$ in combination with $M$. oleifera and G. pentaphyllum using standard doses. Their findings showed a significant curative effect and high percentage suppression in a dosedependent manner. Several other studies have established the efficacy of polyherbal preparations containing $M$. oleifera in combination with other plants, which also inhibited the growth of $P$. falciparum. This holds enormous potential to serve as an excellent source of herbal drug to combat malaria $(112,135,136)$. The crude preparation of the plant leaves in aqueous form also demonstrated antimalarial activities by suppressing $P$. berghei ANKA infection in mice (137). Very recently, Olawoye et al (138) studied the actions of $M$. oleifera powdered leaves on 
amodiaquine (AQ) pharmacokinetics in healthy twenty human volunteers and established a positive interaction between AQ and M. oleifera suggesting a possible combinatorial therapy for malaria. The methanolic seed extract of $M$. oleifera also exhibited significant insecticidal activities, which could be exploited for integrated pest management to control the Anopheles mosquito (139).

\section{Other activities}

The aphrodisiac effect of $M$. oleifera is gaining scientific attention as a supplement to enhance sexual performance, although the precise underlying mechanisms are yet to be understood (140). The leaf extracts of $M$. oleifera inhibited 6 - $\beta$-hydroxylation of testosterone with monoamine modulation effects, which could help to overcome stressinduced male sexual dysfunction $(140,141)$. A significant correlation between increased sexual urges, erectile function, and consumption of $M$. oleifera methanolic leaves extract in rats has been reported and attributed to its soluble epoxide hydrolase inhibitory actions (142). In many local communities in Africa and elsewhere, $M$. oleifera parts have been used in the fight against HIV/AIDs and other viral infections due to its immunostimulatory effects $(24,143,144)$. A study on the impact of leaf powder of $M$. oleifera as a supplement administered to patients with HIV and on antiretroviral therapy significantly enhanced their nutritional intake and boosted their immune system (145). Thus, the antioxidants in M. oleifera can be carefully utilized to fight free radicals and boost immunity in HIV and other related patients.

\section{Toxicity, human studies, and safety of $M$. oleifera}

The study of Reddy et al (146) clearly demonstrated the non-toxic nature of $M$. oleifera bark extracts on rats without records of lethality. Adedapo et al (44) also reported no adverse effect on studied organs and organisms suggesting that $M$. oleifera could be safe on the experimental animals. Likewise, the different tested doses on rats showed no lethality and significant differences in genotoxicity parameters, thus the study confirmed the suitability of $M$. oleifera as a safe herbal drug (62). Asare et al (20) reported that half-maximal lethal dose $\left(\mathrm{LD}_{50}\right)$ of $M$. oleifera aqueous leaf extract was not toxic and observed no changes in the behaviour of the studied rats. In other related studies involving the administration of high dosages of methanolic extract of the plant in male Wistar rats, no toxic reaction or mortality was observed among the rats (147). The toxicity of $M$. oleifera aqueous extract was investigated in both acute and subchronic studies where mice were orally given an extract of $6400 \mathrm{mg} / \mathrm{kg}, 250$, 500 , and $1500 \mathrm{mg} / \mathrm{kg}$, respectively, and intraperitoneally supplied a dose of $1500 \mathrm{mg} / \mathrm{kg}$ and found to be safe (58). In another toxicity evaluation involving different standard doses of $M$. oleifera methanolic extracts for a period of 2 months, there was no negative toxicity reaction on the liver and kidneys of the tested animals (63). According to the findings of the study, all experimental rats fed with $M$. oleifera leaf extract did not show any symptoms of genotoxicity; however, there was an increase in body weight in a dose-dependent manner. Studies of AsieduGyekye (148) also established the safety of a single dose of $5000 \mathrm{mg} / \mathrm{kg}$ and an oral dose of $1000 \mathrm{mg} / \mathrm{kg}$ of M. oleifera in tested rats with no overt adverse effects. Recently, the safety of Moringa isothiocyanate- 1 enriched hydroalcoholic Moringa seeds extract was demonstrated in mid-low rats groups without toxic reactions on the organs (42). Wang et al (105) reported that phenolic glycosides compound 1, 4 and 5 may be developed as new safe hypoglycemic drugs from $M$. oleifera, thus validating its safety as a safe therapeutic agent. The therapeutic effect of M. oleifera consumption on diabetic rats also indicated its possible use and safety as an antidiabetic preparation $(40,149)$. Other studies have also reported and confirmed the safety of $M$. oleifera as an herbal drug to treat many ailments $(59,61,64,148)$.

Several trials demonstrating potential benefits for the treatment of diabetes, ulcer, and asthma and enhancing the immune system of HIV/AIDS patients have been reported $(56,150)$. However, very few clinical trials involving the safety of different preparations of $M$. oleifera parts have been published. Kushwaha et al (150) studied 30 women at post-menopause supplemented daily with $7 \mathrm{~g}$ leaf powder of $M$. oleifera for 12 weeks and compared with another 30 post-menopause women as a control group. There was a corresponding increase in biomarkers of antioxidant properties showing significant anti-hyperglycemic and anti-dyslipidemia activities without toxic effects. Moringa leaf powder could have served as an appetite stimulant in HIV/AIDS patients, thereby improving their immune systems (60). Agrawal and Mehta (64) also investigated clinical trial and safety of the seed kernel of M. oleifera to treat bronchial asthma and demonstrated that the extracts were safe with no adverse effects recorded. Maurya et al (151) conducted a clinical trial of $M$. oleifera stem back on 30 patients with urinary tract infection and reported its safety in humans with no adverse effects reported on the patients. Although genotoxicity at the high dose of the supplement was reported in human peripheral blood mononuclear cells, such doses greatly exceeded commonly used doses as demonstrated by the studies of Asare et al (20). However, at recommended doses administered on rats, $M$. oleifera was found to be safe without genotoxicity observed in the organs tested. Shreds of evidence from the literature and articles retained for this review imply that M. oleifera (leaves, stem and bark or whole leaves) could be safe for consumption as a vegetable, as well as a therapeutic agent to fight diseases and possibly enhance healthy living. Combining the rich pharmacological activities with the safety of $M$. oleifera, this systematic review concludes that $M$. oleifera could be further explored in the search 
for cheaper and safer therapeutic agents against diseases especially in Africa and other resource poor nations.

\section{Conclusion}

This review highlighted the multifaceted pharmacological potentials and safety of $M$. oleifera as a multi-purpose medicinal plant which can be exploited by man in the search for more potent drugs to fight diseases. The increased usage and research efforts on the pharmacological capabilities of the plant (in vivo, in vitro and clinical trials), clearly lend credence to the safety reported in many works of literature and cultures. Though scientific breakthrough has been recorded on many fronts including, identification, isolation, and elucidation of the structure of pharmaceutical principles responsible for many therapeutic actions of $M$. oleifera, more research efforts are needed to ascertain its safety in humans, as well as the safety of current and future potential herbal formulations of Moringa origin. Many Moringa products are already in the market, which requires quality assessment for their safety and consumption. The importance of $M$. oleifera cannot be overemphasized in the search for new bioactives that could be harnessed for therapeutic potentials, and for exploring future research options to be engaged in pharmaceutical and allied companies.

\section{Acknowledgements}

The authors thank the Management of Covenant University and Centre for Research, Innovation, and Discovery (CUCRID) for publication support.

\section{Authors' contributions}

Authors JOP, OSA, OLO, and OOA prepared the manuscript while author OOO supervised the research. All authors contributed equally in planning and carrying out this study. All authors read the manuscript and confirmed the publication for the final version.

\section{Conflict of interest}

We declare no conflicts of interest.

\section{Ethical considerations}

Ethical issues have been observed by the authors.

\section{Funding/Support}

This study received no funding or grant.

\section{References}

1. Anwar F, Latif S, Ashraf M, Gilani AH. Moringa oleifera: a food plant with multiple medicinal uses. Phytother Res. 2007;21(1):17-25. doi: 10.1002/ptr.2023.

2. Popoola JO, Adebayo AH, Taiwo OS, Ayepola OO, Okosodo EF. Studies on local knowledge and in vitro cytotoxicity of Moringa oleifera L., Andrographis paniculata N. and Asystasia vogeliana B. extracts. Res J Appl Sci. 2017;12(2):180-90. doi: 10.36478/rjasci.2017.180.190.
3. Saini RK, Sivanesan I, Keum YS. Phytochemicals of Moringa oleifera: a review of their nutritional, therapeutic and industrial significance. 3 Biotech. 2016;6(2):203. doi: 10.1007/s13205-016-0526-3.

4. Sheba LA, Anuradha V. An updated review on Couroupita guianensis Aubl: a sacred plant of India with myriad medicinal properties. J Herbmed Pharmacol. 2020;9(1):111. doi: 10.15171/jhp.2020.01.

5. Lambert JDN, Ryden PA, Esikuri EE. Capitalizing on the Bio-Economic Value of Multi-Purpose Medicinal Plants for the Rehabilitation of Drylands in Sub-Saharan Africa. Washington, DC, USA. The International Bank for Reconstruction and Development/The World Bank; 2005.

6. Akerele O. Summary of WHO guidelines for the assessment of herbal medicines. Herbal Gram. 1993;28(13):13-9.

7. Karim AA, Azlan A. Fruit pod extracts as a source of nutraceuticals and pharmaceuticals. Molecules. 2012;17(10):11931-46. doi: 10.3390/molecules171011931.

8. Ramabulana T, Mavunda RD, Steenkamp PA, Piater LA, Dubery IA, Madala NE. Perturbation of pharmacologically relevant polyphenolic compounds in Moringa oleifera against photo-oxidative damages imposed by gamma radiation. J Photochem Photobiol B. 2016;156:79-86. doi: 10.1016/j.jphotobiol.2016.01.013.

9. Fatima I, Kanwal S, Mahmood T. Evaluation of biological potential of selected species of family Poaceae from Bahawalpur, Pakistan. BMC Complement Altern Med. 2018;18(1):27. doi: 10.1186/s12906-018-2092-1.

10. Nasr-Bouzaiene N, Sassi A, Bedoui A, Krifa M, ChekirGhedira L, Ghedira K. Immunomodulatory and cellular antioxidant activities of pure compounds from Teucrium ramosissimum Desf. Tumour Biol. 2016;37(6):7703-12. doi: 10.1007/s13277-015-4635-0.

11. Aarland RC, Bañuelos-Hernández AE, Fragoso-Serrano M, Sierra-Palacios ED, Díaz de León-Sánchez F, PérezFlores LJ, et al. Studies on phytochemical, antioxidant, anti-inflammatory, hypoglycaemic and antiproliferative activities of Echinacea purpurea and Echinacea angustifolia extracts. Pharm Biol. 2017;55(1):649-56. doi: 10.1080/13880209.2016.1265989.

12. Hussain S, Malik F, Mahmood S. Review: an exposition of medicinal preponderance of Moringa oleifera (Lank.). Pak J Pharm Sci. 2014;27(2):397-403.

13. Agyare C, Boakye YD, Bekoe EO, Hensel A, Dapaah SO, Appiah T. Review: African medicinal plants with wound healing properties. J Ethnopharmacol. 2016;177:85-100. doi: $10.1016 /$ j.jep.2015.11.008.

14. Tchouya GR, Souza A, Tchouankeu JC, Yala JF, Boukandou $\mathrm{M}$, Foundikou $\mathrm{H}$, et al. Ethnopharmacological surveys and pharmacological studies of plants used in traditional medicine in the treatment of HIV/AIDS opportunistic diseases in Gabon. J Ethnopharmacol. 2015;162:306-16. doi: $10.1016 /$ j.jep.2014.12.052.

15. Hao DC, Gu X, Xiao P. Anemone medicinal plants: ethnopharmacology, phytochemistry and biology. Acta Pharm Sin B. 2017;7(2):146-58. doi: 10.1016/j. apsb.2016.12.001.

16. Chen LL, Verpoorte R, Yen HR, Peng WH, Cheng YC, Chao J, et al. Effects of processing adjuvants on traditional Chinese herbs. J Food Drug Anal. 2018;26(2S):S96-S114. doi: $10.1016 /$ j.jfda.2018.02.004.

17. Kuruvilla A. Herbal formulations as pharmacotherapeutic 
agents. Indian J Exp Biol. 2002;40(1):7-11.

18. Pelkonen O, Pasanen M, Lindon JC, Chan K, Zhao L, Deal G, et al. Omics and its potential impact on R\&D and regulation of complex herbal products. J Ethnopharmacol. 2012;140(3):587-93. doi: 10.1016/j.jep.2012.01.035.

19. Ogunkunle AT, Oyelakin TM, Enitan AO, Oyewole FE. A quantitative documentation of the composition of two powdered herbal formulations (antimalarial and haematinic) using ethnomedicinal information from ogbomoso, Nigeria. Evid Based Complement Alternat Med. 2014;2014:751291. doi: 10.1155/2014/751291.

20. Asare GA, Gyan B, Bugyei K, Adjei S, Mahama R, Addo $\mathrm{P}$, et al. Toxicity potentials of the nutraceutical Moringa oleifera at supra-supplementation levels. J Ethnopharmacol. 2012;139(1):265-72. doi: 10.1016/j.jep.2011.11.009.

21. Ali MA, Yusof YA, Chin NL, Ibrahim MN, Muneer S. Development and standardization of Moringa oleifera leaves as a natural dietary supplement. J Diet Suppl. 2019;16(1):66-85. doi: 10.1080/19390211.2018.1429517.

22. Badejo AA, Damilare A, Ojuade TD. Processing effects on the antioxidant activities of beverage blends developed from Cyperus esculentus, Hibiscus sabdariffa, and Moringa oleifera extracts. Prev Nutr Food Sci. 2014;19(3):227-33. doi: 10.3746/pnf.2014.19.3.227.

23. Abdull Razis AF, Ibrahim MD, Kntayya SB. Health benefits of Moringa oleifera. Asian Pac J Cancer Prev. 2014;15(20):8571-6. doi: 10.7314/apjcp.2014.15.20.8571.

24. Popoola JO, Obembe OO. Local knowledge, use pattern and geographical distribution of Moringa oleifera Lam. (Moringaceae) in Nigeria. J Ethnopharmacol. 2013;150(2):682-91. doi: 10.1016/j.jep.2013.09.043.

25. Abarikwu SO, Benjamin S, Ebah SG, Obilor G, Agbam G. Oral administration of Moringa oleifera oil but not coconut oil prevents mercury-induced testicular toxicity in rats. Andrologia. 2017;49(1). doi: 10.1111/and.12597.

26. Falowo AB, Mukumbo FE, Idamokoro EM, Lorenzo JM, Afolayan AJ, Muchenje V. Multi-functional application of Moringa oleifera Lam. in nutrition and animal food products: a review. Food Res Int. 2018;106:317-34. doi: 10.1016/j.foodres.2017.12.079.

27. Posmontier B. The medicinal qualities of Moringa oleifera. Holist Nurs Pract. 2011;25(2):80-7. doi: 10.1097/ HNP.0b013e31820dbb27.

28. Pirrò S, Zanella L, Kenzo M, Montesano C, Minutolo A, Potestà $\mathrm{M}$, et al. MicroRNA from Moringa oleifera: identification by high throughput sequencing and their potential contribution to plant medicinal value. PLoS One. 2016;11(3):e0149495. doi: 10.1371/journal.pone.0149495.

29. Kou X, Li B, Olayanju JB, Drake JM, Chen N. Nutraceutical or pharmacological potential of Moringa oleifera Lam. Nutrients. 2018;10(3). doi: 10.3390/nu10030343.

30. Dhakad AK, Ikram M, Sharma S, Khan S, Pandey VV, Singh A. Biological, nutritional, and therapeutic significance of Moringa oleifera Lam. Phytother Res. 2019;33(11):2870903. doi: 10.1002/ptr.6475.

31. Mehta K, Balaraman R, Amin AH, Bafna PA, Gulati OD. Effect of fruits of Moringa oleifera on the lipid profile of normal and hypercholesterolaemic rabbits. J Ethnopharmacol. 2003;86(2-3):191-5. doi: 10.1016/s03788741(03)00075-8.

32. Ghasi S, Nwobodo E, Ofili JO. Hypocholesterolemic effects of crude extract of leaf of Moringa oleifera Lam in high-fat diet fed wistar rats. J Ethnopharmacol. 2000;69(1):21-5. doi: 10.1016/s0378-8741(99)00106-3.

33. Mbikay M. Therapeutic potential of Moringa oleifera leaves in chronic hyperglycemia and dyslipidemia: a review. Front Pharmacol. 2012;3:24. doi: 10.3389/fphar.2012.00024.

34. Leone A, Spada A, Battezzati A, Schiraldi A, Aristil J, Bertoli S. Moringa oleifera seeds and oil: characteristics and uses for human health. Int J Mol Sci. 2016;17(12). doi: 10.3390/ ijms17122141.

35. Chiricosta L, Gugliandolo A, Diomede F, Pizzicannella J, Trubiani O, Iori R, et al. Moringin pretreatment inhibits the expression of genes involved in mitophagy in the stem cell of the human periodontal ligament. Molecules. 2019;24(18). doi: 10.3390/molecules24183217.

36. Adejumo OE, Kolapo AL, Folarin AO. Moringa oleifera Lam. (Moringaceae) grown in Nigeria: in vitro antisickling activity on deoxygenated erythrocyte cells. J Pharm Bioallied Sci. 2012;4(2):118-22. doi: 10.4103/0975-7406.94812.

37. Akanni EO, Adedeji AL, Adedosu OT, Olaniran OI, Oloke JK. Chemopreventive and anti-leukemic effects of ethanol extracts of Moringa oleifera leaves on wistar rats bearing benzene induced leukemia. Curr Pharm Biotechnol. 2014;15(6):563-8. doi: 10.2174/1389201015666140717090 755.

38. Bakre AG, Aderibigbe AO, Ademowo OG. Studies on neuropharmacological profile of ethanol extract of Moringa oleifera leaves in mice. J Ethnopharmacol. 2013;149(3):7839. doi: 10.1016/j.jep.2013.08.006.

39. Cáceres A, Cabrera O, Morales O, Mollinedo P, Mendia P. Pharmacological properties of Moringa oleifera. 1: preliminary screening for antimicrobial activity. J Ethnopharmacol. 1991;33(3):213-6. doi: 10.1016/03788741(91)90078-r.

40. Stohs SJ, Hartman MJ. Review of the safety and efficacy of Moringa oleifera. Phytother Res. 2015;29(6):796-804. doi: 10.1002/ptr.5325.

41. Aiello E, Russo R, Cristiano C, Calignano A. The safety assessment of herbals with a new and ethical approach. Nat Prod Res. 2018;32(15):1838-48. doi: $10.1080 / 14786419.2017 .1402316$.

42. Kim Y, Jaja-Chimedza A, Merrill D, Mendes O, Raskin I. A 14-day repeated-dose oral toxicological evaluation of an isothiocyanate-enriched hydro-alcoholic extract from Moringa oleifera Lam. seeds in rats. Toxicol Rep. 2018;5:41826. doi: 10.1016/j.toxrep.2018.02.012.

43. Stournaras E, Tziomalos K. Herbal medicine-related hepatotoxicity. World J Hepatol. 2015;7(19):2189-93. doi: 10.4254/wjh.v7.i19.2189.

44. Adedapo AA, Falayi OO, Oyagbemi AA. Evaluation of the analgesic, anti-inflammatory, anti-oxidant, phytochemical and toxicological properties of the methanolic leaf extract of commercially processed Moringa oleifera in some laboratory animals. J Basic Clin Physiol Pharmacol. 2015;26(5):491-9. doi: 10.1515/jbcpp-2014-0105.

45. Page MJ, Moher D. evaluations of the uptake and impact of the preferred reporting items for systematic reviews and meta-analyses (PRISMA) statement and extensions: a scoping review. Syst Rev. 2017;6(1):263. doi: 10.1186/ s13643-017-0663-8.

46. Siqueira-Lima PS, Silva JC, Quintans JSS, Antoniolli AR, Shanmugam S, Barreto RSS, et al. Natural products assessed in animal models for orofacial pain-a systematic review. 
Rev Bras Farmacogn. 2017;27(1):124-34. doi: 10.1016/j. bjp.2016.06.005.

47. Moura MC, Trentin DS, Napoleão TH, Primon-Barros M, Xavier AS, Carneiro NP, et al. Multi-effect of the watersoluble Moringa oleifera lectin against Serratia marcescens and Bacillus sp.: antibacterial, antibiofilm and anti-adhesive properties. J Appl Microbiol. 2017;123(4):861-74. doi: 10.1111/jam.13556

48. Jaja-Chimedza A, Graf BL, Simmler C, Kim Y, Kuhn P, Pauli GF, et al. Biochemical characterization and antiinflammatory properties of an isothiocyanate-enriched moringa (Moringa oleifera) seed extract. PLoS One. 2017;12(8):e0182658. doi: 10.1371/journal.pone.0182658.

49. Omodanisi EI, Aboua YG, Oguntibeju OO. Assessment of the anti-hyperglycaemic, anti-inflammatory and antioxidant activities of the methanol extract of Moringa oleifera in diabetes-induced nephrotoxic male wistar rats. Molecules. 2017;22(4). doi: 10.3390/molecules22040439.

50. Cheraghi $M$, Namdari $M$, Daraee $H$, Negahdari B. Cardioprotective effect of magnetic hydrogel nanocomposite loaded N,alpha-L-rhamnopyranosyl vincosamide isolated from Moringa oleifera leaves against doxorubicin-induced cardiac toxicity in rats: in vitro and in vivo studies. J Microencapsul. 2017;34(4):335-41. doi: 10.1080/02652048.2017.1311955.

51. Giacoppo S, Iori R, Rollin P, Bramanti P, Mazzon E. Moringa isothiocyanate complexed with alpha-cyclodextrin: a new perspective in neuroblastoma treatment. BMC Complement Altern Med. 2017;17(1):362. doi: 10.1186/ s12906-017-1876-z.

52. Tiloke C, Phulukdaree A, Chuturgoon AA. The antiproliferative effect of Moringa oleifera crude aqueous leaf extract on human esophageal cancer cells. J Med Food. 2016;19(4):398-403. doi: 10.1089/jmf.2015.0113.

53. Jaafaru MS, Nordin N, Shaari K, Rosli R, Abdull Razis AF. Isothiocyanate from Moringa oleifera seeds mitigates hydrogen peroxide-induced cytotoxicity and preserved morphological features of human neuronal cells. PLoS One. 2018;13(5):e0196403. doi: 10.1371/journal.pone.0196403.

54. Muhammad AA, Arulselvan P, Cheah PS, Abas F, Fakurazi S. Evaluation of wound healing properties of bioactive aqueous fraction from Moringa oleifera Lam on experimentally induced diabetic animal model. Drug Des Devel Ther. 2016;10:1715-30. doi: 10.2147/dddt.s96968.

55. Hannan MA, Kang JY, Mohibbullah M, Hong YK, Lee H, Choi JS, et al. Moringa oleifera with promising neuronal survival and neurite outgrowth promoting potentials. J Ethnopharmacol. 2014;152(1):142-50. doi: 10.1016/j. jep.2013.12.036.

56. Devaraj VC, Krishna BG. Antiulcer activity of a polyherbal formulation (PHF) from Indian medicinal plants. Chin J Nat Med. 2013;11(2):145-8. doi: 10.1016/s18755364(13)60041-2.

57. Manaheji H, Jafari S, Zaringhalam J, Rezazadeh S, Taghizadfarid R. Analgesic effects of methanolic extracts of the leaf or root of Moringa oleifera on complete Freund's adjuvant-induced arthritis in rats. Zhong Xi Yi Jie He Xue Bao. 2011;9(2):216-22. doi: 10.3736/jcim20110216.

58. Awodele O, Oreagba IA, Odoma S, da Silva JA, Osunkalu VO. Toxicological evaluation of the aqueous leaf extract of Moringa oleifera Lam. (Moringaceae). J Ethnopharmacol. 2012;139(2):330-6. doi: 10.1016/j.jep.2011.10.008.

59. Chin CY, Ng PY, Ng SF. Moringa oleifera standardised aqueous leaf extract-loaded hydrocolloid film dressing: in vivo dermal safety and wound healing evaluation in STZ/HFD diabetic rat model. Drug Deliv Transl Res. 2019;9(2):453-68. doi: 10.1007/s13346-018-0510-z.

60. Jaafaru MS, Abd Karim NA, Mohamed Eliaser E, Maitalata Waziri P, Ahmed H, Mustapha Barau M, et al. Nontoxic glucomoringin-isothiocyanate (GMG-ITC) rich soluble extract induces apoptosis and inhibits proliferation of human prostate adenocarcinoma cells (PC-3). Nutrients. 2018;10(9). doi: 10.3390/nu10091174.

61. Adedapo AA, Mogbojuri OM, Emikpe BO. Safety evaluations of the aqueous extract of the leaves of Moringa oleifera in rats. J Med Plant Res. 2009;3(8):586-91.

62. Villarruel-López A, López-de la Mora DA, Vázquez-Paulino OD, Puebla-Mora AG, Torres-Vitela MR, Guerrero-Quiroz LA, et al. Effect of Moringa oleifera consumption on diabetic rats. BMC Complement Altern Med. 2018;18(1):127. doi: 10.1186/s12906-018-2180-2.

63. Oyagbemi AA, Omobowale TO, Azeez IO, Abiola JO, Adedokun RA, Nottidge HO. Toxicological evaluations of methanolic extract of Moringa oleifera leaves in liver and kidney of male Wistar rats. J Basic Clin Physiol Pharmacol. 2013;24(4):307-12. doi: 10.1515/jbcpp-2012-0061.

64. Agrawal B, Mehta A. Antiasthmatic activity of Moringa oleifera Lam: a clinical study. Indian J Pharmacol. 2008;40(1):28-31. doi: 10.4103/0253-7613.40486.

65. Chan Sun M, Ruhomally ZB, Boojhawon R, NeergheenBhujun VS. Consumption of Moringa oleifera Lam leaves lowers postprandial blood pressure. J Am Coll Nutr. 2020;39(1):54-62. doi: 10.1080/07315724.2019.1608602.

66. Vergara-Jimenez M, Almatrafi MM, Fernandez ML. Bioactive components in Moringa oleifera leaves protect against chronic disease. Antioxidants (Basel). 2017;6(4). doi: 10.3390/antiox6040091.

67. Bajpai M, Pande A, Tewari SK, Prakash D. Phenolic contents and antioxidant activity of some food and medicinal plants. Int J Food Sci Nutr. 2005;56(4):287-91. doi: $\quad$ 10.1080/09637480500146606.

68. Abarikwu SO, Benjamin S, Ebah SG, Obilor G, Agbam G. Protective effect of Moringa oleifera oil against $\mathrm{HgCl} 2$ induced hepato- and nephro-toxicity in rats. J Basic Clin Physiol Pharmacol. 2017;28(4):337-45. doi: 10.1515/ jbcpp-2016-0033.

69. Fakurazi S, Hairuszah I, Nanthini U. Moringa oleifera Lam prevents acetaminophen induced liver injury through restoration of glutathione level. Food Chem Toxicol. 2008;46(8):2611-5. doi: 10.1016/j.fct.2008.04.018.

70. Chumark P, Khunawat P, Sanvarinda Y, Phornchirasilp $S$, Morales NP, Phivthong-Ngam L, et al. The in vitro and ex vivo antioxidant properties, hypolipidaemic and antiatherosclerotic activities of water extract of Moringa oleifera Lam. leaves. J Ethnopharmacol. 2008;116(3):43946. doi: 10.1016/j.jep.2007.12.010.

71. Gupta R, Dubey DK, Kannan GM, Flora SJ. Concomitant administration of Moringa oleifera seed powder in the remediation of arsenic-induced oxidative stress in mouse. Cell Biol Int. 2007;31(1):44-56. doi: 10.1016/j. cellbi.2006.09.007.

72. Adepoju-Bello AA, Jolayemi OM, Ehianeta TS, Ayoola GA. Preliminary phytochemical screening, antioxidant and antihyperglycaemic activity of Moringa oleifera leaf extracts. Pak J Pharm Sci. 2017;30(6):2217-22.

73. Galuppo M, Giacoppo S, De Nicola GR, Iori R, Navarra 
M, Lombardo GE, et al. Antiinflammatory activity of glucomoringin isothiocyanate in a mouse model of experimental autoimmune encephalomyelitis. Fitoterapia. 2014;95:160-74. doi: 10.1016/j.fitote.2014.03.018.

74. Giacoppo S, Rajan TS, De Nicola GR, Iori R, Rollin $\mathrm{P}$, Bramanti $\mathrm{P}$, et al. The Isothiocyanate Isolated from Moringa oleifera shows potent anti-inflammatory activity in the treatment of murine subacute Parkinson's disease. Rejuvenation Res. 2017;20(1):50-63. doi: 10.1089/ rej.2016.1828.

75. Adedapo A, Falayi O, Oyagbemi A. The anti-oxidant, antiinflammatory and antinociceptive activities of the methanol leaf extract of Moringa oleifera in some laboratory animals (657.19). FASEB J. 2014;28(1_Supplement):657.19.

76. Omodanisi EI, Aboua YG, Chegou NN, Oguntibeju OO. Hepatoprotective, antihyperlipidemic, and antiinflammatory activity of Moringa oleifera in diabeticinduced damage in male wistar rats. Pharmacognosy Res. 2017;9(2):182-7. doi: 10.4103/0974-8490.204651.

77. Paikra BK, Dhongade HKJ, Gidwani B. Phytochemistry and pharmacology of Moringa oleifera Lam. J Pharmacopuncture. 2017;20(3):194-200. doi: 10.3831/ kpi.2017.20.022.

78. Padla EP, Solis LT, Levida RM, Shen CC, Ragasa CY. Antimicrobial isothiocyanates from the seeds of Moringa oleifera Lam. Z Naturforsch C J Biosci. 2012;67(11-12):55764. doi: 10.1515/znc-2012-11-1205.

79. Neto JXS, Pereira ML, Oliveira JTA, Rocha-Bezerra LCB, Lopes TDP, Costa HPS, et al. A chitin-binding protein purified from Moringa oleifera seeds presents anticandidal activity by increasing cell membrane permeability and reactive oxygen species production. Front Microbiol. 2017;8:980. doi: 10.3389/fmicb.2017.00980.

80. Elgamily H, Moussa A, Elboraey A, El-Sayed H, AlMoghazy M, Abdalla A. Microbiological assessment of Moringa oleifera extracts and its incorporation in novel dental remedies against some oral pathogens. Open Access Maced J Med Sci. 2016;4(4):585-90. doi: 10.3889/ oamjms.2016.132.

81. Dzotam JK, Touani FK, Kuete V. Antibacterial and antibiotic-modifying activities of three food plants (Xanthosoma mafaffa Lam., Moringa oleifera (L.) Schott and Passiflora edulis Sims) against multidrug-resistant (MDR) Gram-negative bacteria. BMC Complement Altern Med. 2016;16:9. doi: 10.1186/s12906-016-0990-7.

82. Eiamphungporn W, Schaduangrat N, Malik AA, Nantasenamat C. Tackling the antibiotic resistance caused by class A beta-Lactamases through the use of betaLactamase inhibitory protein. Int J Mol Sci. 2018;19(8). doi: 10.3390/ijms19082222.

83. Gould IM, Bal AM. New antibiotic agents in the pipeline and how they can help overcome microbial resistance. Virulence. 2013;4(2):185-91. doi: 10.4161/viru.22507.

84. Fard MT, Arulselvan P, Karthivashan G, Adam SK, Fakurazi S. Bioactive extract from Moringa oleifera inhibits the proinflammatory mediators in lipopolysaccharide stimulated macrophages. Pharmacogn Mag. 2015;11(Suppl 4):S55663. doi: 10.4103/0973-1296.172961.

85. Maldini M, Maksoud SA, Natella F, Montoro P, Petretto GL, Foddai M, et al. 'Moringa oleifera: study of phenolics and glucosinolates by mass spectrometry'. J Mass Spectrom. 2014;49(9):900-10. doi: 10.1002/jms.3437.

86. Cirmi S, Ferlazzo N, Gugliandolo A, Musumeci L, Mazzon
E, Bramanti A, et al. Moringin from Moringa oleifera seeds inhibits growth, arrests cell-cycle, and induces apoptosis of SH-SY5Y human neuroblastoma cells through the modulation of NF-kappaB and apoptotic related factors. Int J Mol Sci. 2019;20(8). doi: 10.3390/ijms20081930.

87. Tiloke C, Phulukdaree A, Chuturgoon AA. The antiproliferative effect of Moringa oleifera crude aqueous leaf extract on cancerous human alveolar epithelial cells. BMC Complement Altern Med. 2013;13:226. doi: 10.1186/1472-6882-13-226.

88. Wang L, Zou Q, Wang J, Zhang J, Liu Z, Chen X. Proteomic profiles reveal the function of different vegetative tissues of Moringa oleifera. Protein J. 2016;35(6):440-7. doi: 10.1007/ s10930-016-9690-x.

89. Al-Asmari AK, Albalawi SM, Athar MT, Khan AQ, AlShahrani H, Islam M. Moringa oleifera as an anti-cancer agent against breast and colorectal cancer cell lines. PLoS One. 2015;10(8):e0135814. doi: 10.1371/journal. pone. 0135814 .

90. Antonini E, Iori R, Ninfali P, Scarpa ES. A combination of Moringin and Avenanthramide $2 \mathrm{f}$ inhibits the proliferation of Hep3B liver cancer cells inducing intrinsic and extrinsic apoptosis. Nutr Cancer. 2018;70(7):1159-65. doi: 10.1080/01635581.2018.1497672.

91. Agrawal ND, Nirala SK, Shukla S, Mathur R. Coadministration of adjuvants along with Moringa oleifera attenuates beryllium-induced oxidative stress and histopathological alterations in rats. Pharm Biol. 2015;53(10):1465-73. doi: 10.3109/13880209.2014.986685.

92. Diab KA, Guru SK, Bhushan S, Saxena AK. In vitro anticancer activities of Anogeissus latifolia, Terminalia bellerica, Acacia catechu and Moringa oleiferna Indian plants. Asian Pac J Cancer Prev. 2015;16(15):6423-8. doi: 10.7314/apjcp.2015.16.15.6423.

93. Tiloke C, Anand K, Gengan RM, Chuturgoon AA. Moringa oleifera and their phytonanoparticles: potential antiproliferative agents against cancer. Biomed Pharmacother. 2018;108:457-66. doi: 10.1016/j. biopha.2018.09.060.

94. Anand K, Tiloke C, Phulukdaree A, Ranjan B, Chuturgoon A, Singh S, et al. Biosynthesis of palladium nanoparticles by using Moringa oleifera flower extract and their catalytic and biological properties. J Photochem Photobiol B. 2016;165:87-95. doi: 10.1016/j.jphotobiol.2016.09.039.

95. Khalil WK, Ghaly IS, Diab KA, Elmakawy AI. Antitumor activity of Moringa oleifera leaf extract against Ehrlich solid tumor. Int J Pharm. 2014;4(3):68-82.

96. Amaeze OU, Aderemi-Williams RI, Ayo-Vaughan MA, Ogundemuren DA, Ogunmola DS, Anyika EN. Herbal medicine use among Type 2 diabetes mellitus patients in Nigeria: understanding the magnitude and predictors of use. Int J Clin Pharm. 2018;40(3):580-8. doi: 10.1007/ s11096-018-0648-2.

97. Guthrie RA, Guthrie DW. Pathophysiology of diabetes mellitus. Crit Care Nurs Q. 2004;27(2):113-25. doi: 10.1097/00002727-200404000-00003.

98. Unnikrishnan R, Anjana RM, Mohan V. Diabetes mellitus and its complications in India. Nat Rev Endocrinol. 2016;12(6):357-70. doi: 10.1038/nrendo.2016.53.

99. Tao Z, Shi A, Zhao J. Epidemiological perspectives of diabetes. Cell Biochem Biophys. 2015;73(1):181-5. doi: 10.1007/s12013-015-0598-4.

100. Zimmet P, Alberti KG, Magliano DJ, Bennett PH. Diabetes 
mellitus statistics on prevalence and mortality: facts and fallacies. Nat Rev Endocrinol. 2016;12(10):616-22. doi: 10.1038/nrendo.2016.105.

101. Roglic G. WHO Global report on diabetes: a summary. Int J Noncommun Dis. 2016;1(1):3-8.

102. Awodele O, Daniel A, Popoola TD, Salami EF. A study on pharmacovigilance of herbal medicines in Lagos West Senatorial District, Nigeria. Int J Risk Saf Med. 2013;25(4):205-17. doi: 10.3233/jrs-130604.

103. Abd Eldaim MA, Shaban Abd Elrasoul A, Abd Elaziz SA. An aqueous extract from Moringa oleifera leaves ameliorates hepatotoxicity in alloxan-induced diabetic rats. Biochem Cell Biol. 2017;95(4):524-30. doi: 10.1139/bcb-2016-0256.

104. Waterman C, Rojas-Silva P, Tumer TB, Kuhn P, Richard AJ, Wicks S, et al. Isothiocyanate-rich Moringa oleifera extract reduces weight gain, insulin resistance, and hepatic gluconeogenesis in mice. Mol Nutr Food Res. 2015;59(6):1013-24. doi: 10.1002/mnfr.201400679.

105. Wang F, Zhong HH, Chen WK, Liu QP, Li CY, Zheng YF, et al. Potential hypoglycaemic activity phenolic glycosides from Moringa oleifera seeds. Nat Prod Res. 2017;31(16):1869-74. doi: 10.1080/14786419.2016.1263846.

106. Jaiswal D, Kumar Rai P, Kumar A, Mehta S, Watal G. Effect of Moringa oleifera Lam. leaves aqueous extract therapy on hyperglycemic rats. J Ethnopharmacol. 2009;123(3):392-6. doi: 10.1016/j.jep.2009.03.036.

107. Jaiswal D, Rai PK, Mehta S, Chatterji S, Shukla S, Rai DK, et al. Role of Moringa oleifera in regulation of diabetes-induced oxidative stress. Asian Pac J Trop Med. 2013;6(6):426-32. doi: 10.1016/s1995-7645(13)60068-1.

108. Yassa HD, Tohamy AF. Extract of Moringa oleifera leaves ameliorates streptozotocin-induced Diabetes mellitus in adult rats. Acta Histochem. 2014;116(5):844-54. doi: 10.1016/j.acthis.2014.02.002.

109. Alejandra Sánchez-Muñoz M, Valdez-Solana MA, CamposAlmazán MI, Flores-Herrera Ó, Esparza-Perusquía M, Olvera-Sánchez S, et al. Streptozotocin-induced adaptive modification of mitochondrial supercomplexes in liver of wistar rats and the protective effect of Moringa oleifera Lam. Biochem Res Int. 2018;2018:5681081. doi: 10.1155/2018/5681081.

110. Leone A, Bertoli S, Di Lello S, Bassoli A, Ravasenghi S, Borgonovo G, et al. Effect of Moringa oleifera leaf powder on postprandial blood glucose response: in vivo study on Saharawi people living in refugee camps. Nutrients. 2018;10(10). doi: 10.3390/nu10101494.

111. Barichella M, Pezzoli G, Faierman SA, Raspini B, Rimoldi $\mathrm{M}$, Cassani E, et al. Nutritional characterisation of Zambian Moringa oleifera: acceptability and safety of short-term daily supplementation in a group of malnourished girls. Int J Food Sci Nutr. 2019;70(1):107-15. doi: 10.1080/09637486.2018.1475550.

112. Ranasinghe S, Ansumana R, Lamin JM, Bockarie AS, Bangura U, Buanie JA, et al. Herbs and herbal combinations used to treat suspected malaria in Bo, Sierra Leone. J Ethnopharmacol. 2015;166:200-4. doi: 10.1016/j. jep.2015.03.028.

113. Parfrey PS, Foley RN. The clinical epidemiology of cardiac disease in chronic renal failure. J Am Soc Nephrol. 1999;10(7):1606-15.

114. National Institutes of Health. US Renal Data System, USRDS 1998 Annual Data Report. http://www.usrds.org/ adr_1998.htm. 1998.

115. Randriamboavonjy JI, Loirand G, Vaillant N, Lauzier B, Derbré S, Michalet S, et al. Cardiac protective effects of Moringa oleifera seeds in spontaneous hypertensive rats. Am J Hypertens. 2016;29(7):873-81. doi: 10.1093/ajh/ hpw001.

116. Chen KH, Chen YJ, Yang CH, Liu KW, Chang JL, Pan SF, et al. Attenuation of the extract from Moringa oleifera on monocrotaline-induced pulmonary hypertension in rats. Chin J Physiol. 2012;55(1):22-30. doi: 10.4077/cjp.2012. amm 104

117. Azeez IA, Yusuf BO. Case finding of hypertension at a secondary health care facility in south-west Nigeria. Ann Ib Postgrad Med. 2018;16(1):44-51.

118. Attakpa ES, Bertin GA, Chabi NW, Ategbo JM, Seri B, Khan NA. Moringa oleifera-rich diet and T cell calcium signaling in spontaneously hypertensive rats. Physiol Res. 2017;66(5):753-67. doi: 10.33549/physiolres.933397.

119. Randriamboavonjy JI, Rio M, Pacaud P, Loirand G, Tesse A. Moringa oleifera seeds attenuate vascular oxidative and nitrosative stresses in spontaneously hypertensive rats. Oxid Med Cell Longev. 2017;2017:4129459. doi: $10.1155 / 2017 / 4129459$.

120. Nandave M, Ojha SK, Joshi S, Kumari S, Arya DS. Moringa oleifera leaf extract prevents isoproterenol-induced myocardial damage in rats: evidence for an antioxidant, antiperoxidative, and cardioprotective intervention. J Med Food. 2009;12(1):47-55. doi: 10.1089/jmf.2007.0563.

121. Gothai S, Arulselvan P, Tan WS, Fakurazi S. Wound healing properties of ethyl acetate fraction of Moringa oleifera in normal human dermal fibroblasts. J Intercult Ethnopharmacol. 2016;5(1):1-6. doi: 10.5455/ jice.20160201055629.

122. Choudhary MK, Bodakhe SH, Gupta SK. Assessment of the antiulcer potential of Moringa oleifera root-bark extract in rats. J Acupunct Meridian Stud. 2013;6(4):214-20. doi: 10.1016/j.jams.2013.07.003.

123. World Health Organization (WHO). Investing to Overcome the Global Impact of Neglected Tropical Diseases: Third WHO Report on Neglected Tropical Diseases 2015. Geneva: WHO; 2015.

124. Ruckmani K, Kavimani S, Jayakar B, Anandan R. Anti-ulcer activity of the alkali preparation of the root and fresh leaf juice of Moringa oleifera lam. Anc Sci Life. 1998;17(3):2203.

125. Das D, Dash D, Mandal T, Kishore A, Bairy KL. Protective effects of Moringa oleifera on experimentally induced gastric ulcers in rats. Res J Pharm Biol Chem Sci. 2011;2(2):50-5.

126. Cáceres A, Saravia A, Rizzo S, Zabala L, De Leon E, Nave F. Pharmacologic properties of Moringa oleifera. 2: screening for antispasmodic, antiinflammatory and diuretic activity. J Ethnopharmacol. 1992;36(3):233-7. doi: 10.1016/03788741(92)90049-w.

127. Whitney JD. Overview: acute and chronic wounds. Nurs Clin North Am. 2005;40(2):191-205, v. doi: 10.1016/j. cnur.2004.09.002.

128. White NJ, Pukrittayakamee S, Hien TT, Faiz MA, Mokuolu OA, Dondorp AM. Malaria. Lancet. 2014;383(9918):72335. doi: 10.1016/s0140-6736(13)60024-0.

129. World Health Organization (WHO). Guidelines for the Treatment of Malaria. Geneva: WHO; 2015.

130. Nkumama IN, O'Meara WP, Osier FHA. Changes in 
malaria epidemiology in Africa and new challenges for elimination. Trends Parasitol. 2017;33(2):128-40. doi: 10.1016/j.pt.2016.11.006.

131. Ajayi IO, Ughasoro MD, Ogunwale A, Odeyinka O, Babalola $\mathrm{O}$, Sharafadeen S, et al. A qualitative exploration of malaria operational research situation in Nigeria. PLoS One. 2017;12(11):e0188128. doi: 10.1371/journal.pone.0188128.

132. Guyant P, Corbel V, Guerin PJ, Lautissier A, Nosten F, Boyer $S$, et al. Past and new challenges for malaria control and elimination: the role of operational research for innovation in designing interventions. Malar J. 2015;14:279. doi: 10.1186/s12936-015-0802-4.

133. Bello OA, Ayanda OI, Aworunse OS, Olukanmi BI, Soladoye MO, Esan EB, et al. Solanecio biafrae: an underutilized nutraceutically-important African indigenous vegetable. Pharmacogn Rev. 2018;12(23):128-32. doi: 10.4103/phrev. phrev_43_17.

134. Memvanga PB, Tona GL, Mesia GK, Lusakibanza MM, Cimanga RK. Antimalarial activity of medicinal plants from the Democratic Republic of Congo: a review. J Ethnopharmacol. 2015;169:76-98. doi: 10.1016/j. jep.2015.03.075.

135. Somsak V, Borkaew P, Klubsri C, Dondee K, Bootprom P, Saiphet B. Antimalarial properties of aqueous crude extracts of Gynostemma pentaphyllum and Moringa oleifera leaves in combination with artesunate in Plasmodium bergheiinfected mice. J Trop Med. 2016;2016:8031392. doi: 10.1155/2016/8031392.

136. Gonzalez AC, Costa TF, Andrade ZA, Medrado AR. Wound healing - A literature review. An Bras Dermatol. 2016;91(5):614-20. doi: 10.1590/abd1806-4841.20164741.

137. Dondee K, Bootprom P, Saiphet B, Borkaew P, Klubsri C, Somsak V. Antimalarial activities of Moringa oleifera leaf extract against Plasmodium berghei ANKA infection in ICR mice. Int J Innov Res Med Sci. 2016;1(5):194-201.

138. Olawoye OS, Adeagbo BA, Bolaji OO. Moringa oleifera leaf powder alters the pharmacokinetics of amodiaquine in healthy human volunteers. J Clin Pharm Ther. 2018;43(5):626-32. doi: 10.1111/jcpt.12725.

139. Prabhu K, Murugan K, Nareshkumar A, Ramasubramanian $\mathrm{N}$, Bragadeeswaran S. Larvicidal and repellent potential of Moringa oleifera against malarial vector, Anopheles stephensi Liston (Insecta: Diptera: Culicidae). Asian Pac J Trop Biomed. 2011;1(2):124-9. doi: 10.1016/s22211691(11)60009-9.

140. Prabsattroo T, Wattanathorn J, Iamsaard S, Somsapt P, Sritragool O, Thukhummee W, et al. Moringa oleifera extract enhances sexual performance in stressed rats. J Zhejiang Univ Sci B. 2015;16(3):179-90. doi: 10.1631/jzus. B1400197.

141. Monera TG, Wolfe AR, Maponga CC, Benet LZ, Guglielmo J. Moringa oleifera leaf extracts inhibit 6beta-hydroxylation of testosterone by CYP3A4. J Infect Dev Ctries. 2008;2(5):37983. doi: 10.3855/jidc. 201.

142. Goswami SK, Inamdar MN, Dethe SM, Gururaj GM, Jamwal R, Bhaskar A, et al. Erectogenic and aphrodisiac property of Moringa oleifera: involvement of soluble epoxide hydrolase enzyme. Phytother Res. 2016;30(7):1119-27. doi: 10.1002/ ptr.5614.

143. Biswas SK, Chowdhury A, Das J, Roy A, Hosen SMZ. Pharmacological potentials of Moringa oleifera Lam.: a review. Int J Pharm Sci Res. 2012;3(2):305-10. doi: 10.13040/ IJPSR.0975-8232.3(2).305-10.

144. Endale Gurmu A, Teni FS, Tadesse WT. Pattern of traditional medicine utilization among HIV/AIDS patients on antiretroviral therapy at a university hospital in Northwestern Ethiopia: a cross-sectional study. Evid Based Complement Alternat Med. 2017;2017:1724581. doi: 10.1155/2017/1724581.

145. Tshingani K, Donnen P, Mukumbi H, Duez P, DramaixWilmet M. Impact of Moringa oleifera lam. Leaf powder supplementation versus nutritional counseling on the body mass index and immune response of HIV patients on antiretroviral therapy: a single-blind randomized control trial. BMC Complement Altern Med. 2017;17(1):420. doi: 10.1186/s12906-017-1920-z.

146. Reddy YR, Lokanatha O, Ratnam KS, Reddy CS, Raju IN, Reddy CD. Acute and sub-acute toxicity of Moringa oleifera stem bark extract in Swiss albino mice. Int J Life Sci Biotechnol Pharma Res. 2013;2(4):73-82.

147. Bais S, Singh GS, Sharma R. Antiobesity and hypolipidemic activity of Moringa oleifera leaves against high fat dietinduced obesity in rats. Adv Biol. 2014;2014:162914. doi: $10.1155 / 2014 / 162914$.

148. Asiedu-Gyekye IJ, Frimpong-Manso S, Awortwe C, Antwi DA, Nyarko AK. Micro-and macroelemental composition and safety evaluation of the nutraceutical Moringa oleifera leaves. J Toxicol. 2014;2014:786979. doi: $10.1155 / 2014 / 786979$.

149. Abd El Latif A, El Bialy Bel S, Mahboub HD, Abd Eldaim MA. Moringa oleifera leaf extract ameliorates alloxaninduced diabetes in rats by regeneration of beta cells and reduction of pyruvate carboxylase expression. Biochem Cell Biol. 2014;92(5):413-9. doi: 10.1139/bcb-2014-0081.

150. Kushwaha S, Chawla P, Kochhar A. Effect of supplementation of drumstick (Moringa oleifera) and amaranth (Amaranthus tricolor) leaves powder on antioxidant profile and oxidative status among postmenopausal women. J Food Sci Technol. 2014;51(11):3464-9. doi: 10.1007/s13197-012-0859-9.

151. Maurya SK, Singh AK. Clinical efficacy of Moringa oleifera Lam. Stems bark in urinary tract infections. Int Sch Res Notices. 2014;2014:906843. doi: 10.1155/2014/906843. 